\title{
Towards Applying HCI Theory for Designing IMBMap: A New Assistive Technology to Support Independent Mobility of Visually Impaired and Blind People
}

\author{
Sara Jeza Alotaibi \\ College of Computer Science and Information Technology \\ Taif University, Taif, Saudi Arabia
}

\begin{abstract}
Visually impaired or blind people are often dependent on the others to make a journey from one place to the other. Due to the advent of assistive technology, many tools and devices have been developed to help the blind people make displacement safely and independently. This paper presents some of these devices that are categorized as the following; electronic travels aids, electronic orientation aids, navigational systems etc.
\end{abstract}

\section{Introduction}

From World Health Organization, the number of the World Population is increasing at every moment. In 2013, the figure was seem to amount to approximately $6,809,551,260$. According to these statistics, there are 314 million people globally who are visually impaired, amongst whom 45 million are blind. Almost two-thirds of blind people worldwide are women.

For most people who are blind, walking in an unknown environment can be unpleasant and uncomfortable, even following extensive orientation and mobility (O\&M) rehabilitation training. Visually impaired and blind people tend to face problems whilst travelling alone since they do not have a visual perception and orientation of their environment. Firstly, they face problems in acquiring information for planning their journey. After they have overcome this and have initial basic information, they face difficulties in keeping track of their planned journey and judging whether they are going off-track [2].

The term 'assistive technology' is commonly used to indicate technology that is designed for people with some kind of disability [2]. Over the years, it has been researched and concluded that the best quality about an assistive technology is that it performs the task without the person having to think about the technology itself [1]. For such a large group of people, necessary solutions should be provided to make them independent in terms of their mobility and work [3]. People who have severe visual impairments face many hurdles in accomplishing independent mobility which would be safe and reliable for them [4]. There are several good assistive technological equipments and solutions available but some have serious drawbacks [5]. These assistive technological solutions have their own advantages and limitations [8]. It has been reported that assistive technologies are highly used by blind users however some researchers have also discussed the abandonment of such devices by the users after sometime [12].

The paper is structured in the following manner; Firstly, the background of the subject is explained in Section 2. This is followed by a critical review of technologies that have been developed for the blind to provide them assistance. Then, Section 4 shows evaluation of these solutions and technologies. Then, Section 5 shows different design HCI methods that will use in this study. Finally, Section 6 concludes the paper with a summary and future work.

\section{Historical Overview}

Visually impaired and blind people tend to face problem while travelling alone since they do not have a visual perception and orientation of their environment. Firstly, they face problems in acquiring information for planning their journey. After they have overcome this and have initial basic information, they face difficulties in keeping track of their planned journey and judging if they are going off-track [2].

Research on the orientation and mobility skills of people who are blind in known and unknown spaces indicates that the support for the acquisition of spatial mapping and orientation skills should be supplied at two main levels, namely perceptual and conceptual:

- At the perceptual level: deficiency in the visual channel should be compensated by information perceived via other senses. Thus, the haptic, audio and smell channels become powerful information 
suppliers surrounding unknown environments.

- At the conceptual level: the focus is on supporting the development of appropriate strategies for an efficient mapping of the space and the generation of navigation paths.

Electronic travel aids (ETAs) are most important for blind and visually impaired so that they do not have to depend on any other individual for their displacement [3]. Some of the ETAs that have been proposed over the years are Mowat sensor [15], Teletact and VigitTack [16]; these are used for assistance to avoid obstacles.

Robotic development has also taken place in this field and many tools and inventions have been witnessed. In 2004, Iwatsuka [17] invented the robotic dog; they claimed it to be a smart vision based walker which was equipped with the speech recognition mechanism. Cameras were placed at human height to facilitate the experience of a normal sighted person. Another solution that has been devised over time is the use of smart electronic canes. Canes are used by around 4 million people in US as they provide the basic biomechanical required support for being mobile [18]. Canes cannot be termed as most efficient when obstacles are involved such as stairs, and surfaces with probable friction etc [19]. For such scenarios; active guidance is required to train the potential cane users [5].

Many systems have been developed to provide information to the blind that would be useful for a comprehensive mapping of the space around them and thus generation of navigational paths [20]; some systems proposed in the past are Kaspa [21], activated audio beacon by using cell phones technology [22].

\section{Other Solutions by using Technological Assistance}

The technologies that have been developed for the blind to provide them assistance in being mobile can be discussed in different categories; traditional lowtech aids, ETAs [18], EOAs, assistance for navigation purposes and assistance for (specifically) mobility. One research paper has been chosen for each category that reflects a clear understanding of the subject.

\subsection{Traditional Low-Tech Aids}

The paper chosen for this category is [6]. The most common aid of the past has been the traditional white cane which is lightweight, inexpensive and easy to carry. Guide dogs were also used for such purposes. However the usage of the white cane requires some degree and guidance to avoid any falling [10].

\subsection{Electronic Travel Aids Medium Tech (ETA)}

Technological Canes: One of the papers chosen for this research is [23]; to explain the technology about intelligent canes is about "Robotic Cane". This paper gives a comprehensive explanation regarding the working and design of their robot. There has been a lot of development in the robotics field [9]. Blind people usually use a white cane or a guide dog (which is a trained dog to navigate the way for the blind) [24]. The advantages of the traditional cane and the guide dog have been observed and have proposed an interactive robotic cane [23]. They named the robotic cane "RoJi" ; it is powered with two motors so that it can guide the person with sufficient power.

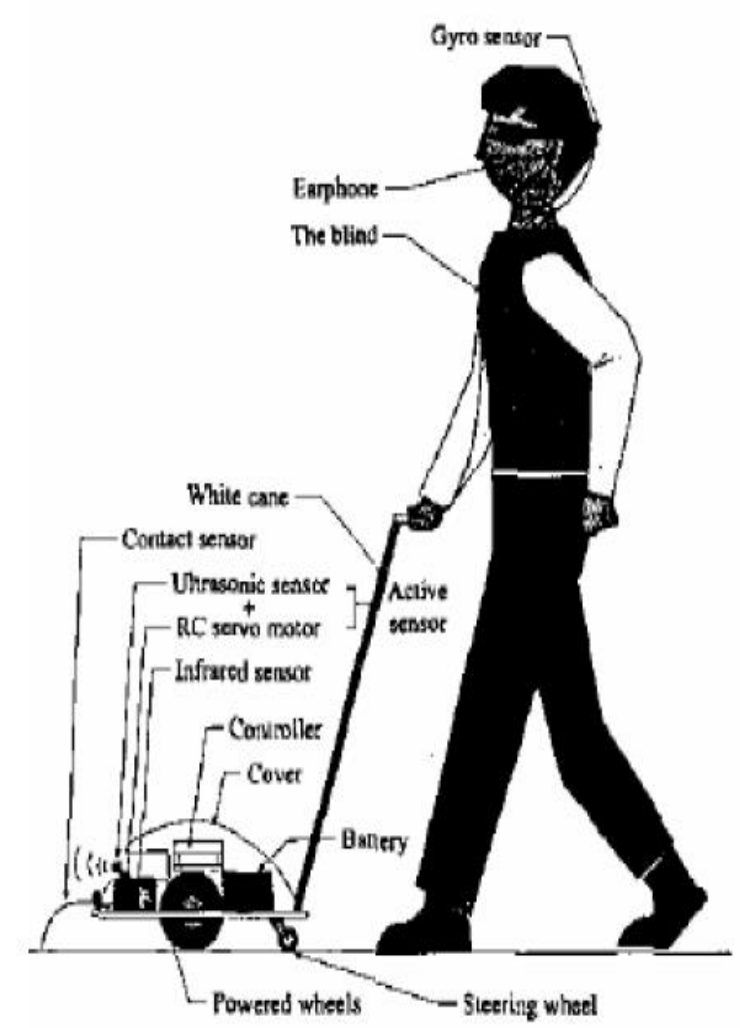

Figure 1: Robotic Cane [23]

There is an ultrasonic sensor driven at RC motor; mounted above the wheels. It scans the space in front of it to detect any obstacles or hazards. It scans the area ahead at an angle of (+-) 900. Another example of Electronic cane is Smart Cane [23]; just like the robotic cane, it is also powered with wheels and sensors for obstacle detection.

Another paper chosen for ETA is the Intelligent Glasses [16] which is a new sensory substitution to a 
sequential time-consuming environmental scan by electronic canes. It proposes a vision similar to a 3D world on a tactile display [16].

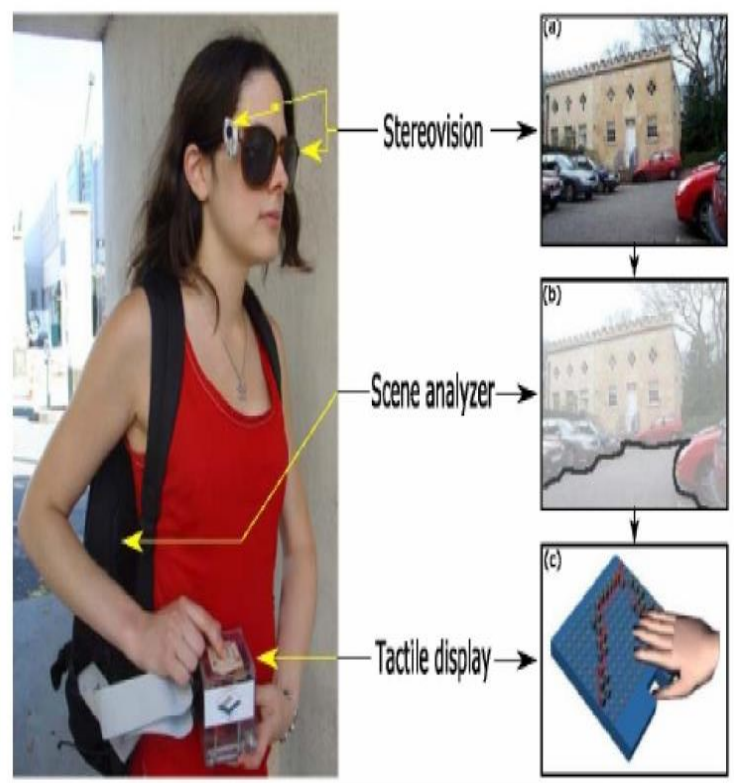

Figure 2: IG system and an example of its image-totactile rendering [16]

\subsection{Electronic Orientation Aids}

A system has been proposed in the chosen paper [14] for orientation aid to the blind users; it is the electron neural vision system (ENVS). This paper has been chosen because it supports a portable system to give outdoor navigation incorporates by GPS. One of the main features of this innovative system is to enable the user to avoid obstacles and provide navigation in outdoors [14]. It consists of a headset with two stereo cameras, digital compass and a computer with GPS capabilities. A depth map is created by the cameras, the portable computer is used to convert the information of the depth map and obstacles. This is sent to the electronic glove TENS in the form of electrical pulses that cause sensations in the finger. "The amount of stimulation is directly proportional to the distance of the objects in the direction pointed by each finger." [14].
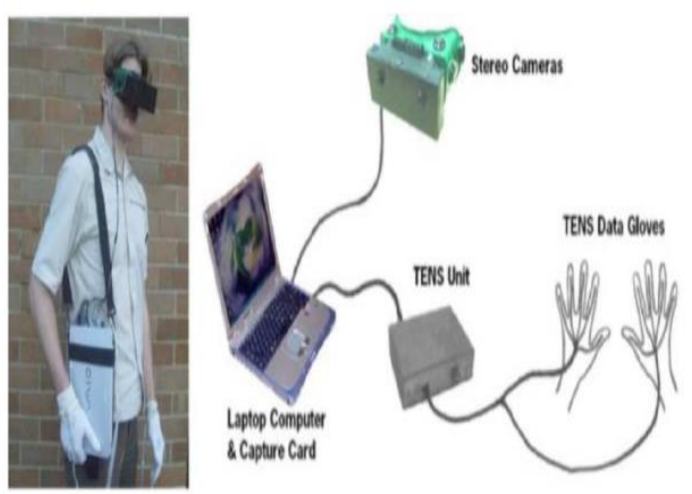

Figure 3: ENVS with its components [14]

\subsection{Assistance for Navigation}

A paper has been chosen for navigation system proposed in [13] - Tylfos; it is based on two modules- Reader and Navigator. This paper has been chosen because Tylfos proposes a unique technique of obstacle detection; it is done in $\mathrm{x}$, $\mathrm{y}$ coordinates. The main aim of this system is to integrate different navigation technologies like wireless handheld computer, GPS sensors and text-to speech devices so that the user is given correct navigational instructions. The output of the directions is given a tactile display. The role of the Navigator in this system is to capture environmental data from all the sensors and deliver this information to the user in the most appropriate manner.

\subsection{Assistance for Mobility}

Another system is chosen from the paper [14]; it has different systems described in the paper. One of the systems in it is CyARM; they claim that the main feature of this system is to provide aid in guiding orientation and mobility. It uses the ultrasonic sensors to detect the hurdles that might be present in a way. Along with the obstacles, it measures the distance between the object and the user. This feature will help him during his mobility as he will get the exact distance between the present objects. The information is delivered to the user via the tension of a wire that is attached to him for example with his belt. High tension in the wire will indicate that he is close to an object; so close that he might be able to touch if hand is extended. Low tension in the wire will indicate longer distance [11].

\section{Evaluation of Solutions}

Wayfinding can be defined as a technique adapted by blind people as they move from one place to the other without being dependent on anyone [7]. It involves two categories; orientation and mobility. 
Orientation is the capability of a person to be able to judge where they currently are and to judge one's position in the environment. Mobility involves the ability of an individual to travel safely while detecting hurdles and obstacles [7]. Navigation involves the synchronized combination of both sensory and cognitive skills [20]. Spatial Perception involves the ability of the person to determine the horizontal and vertical directions in a specific space; where distracting patterns may also be present [23].

The authors of paper [6] states that canes help in immediate and surface located obstacles. However they do not address the fact that low-tech canes do not give information about the distance that the objects might be at or at what height. Another set of authors [23] analyzed the usage of canes and stated that their Robotic Cane helps the blind travelers to navigate through their journey and detect the obstacles or other hazards that might prevail in the environment. They stated that the robotic cane makes independent decisions about the path; however limitation lies when the user might want to have control over the path that he takes. That is when the normal mode must be overridden to allow the user to take control of the robot. The main difference between the two technologies of Robotic cane and another cane named- Smart Cane is that Robotic cane scans the area ahead at an angle of $90^{\circ}$ while the Smart Cane scans it at $45^{\circ}$. This makes the Smart Cane more accurate and detailed in terms of detecting obstacles.

The authors for ENVS stated that training is required for the usage of canes, whereas the testing phase of ENVS concluded that the users were able to reach their destination while avoiding obstacles and with minimum training [14].

The authors of the chosen navigation system Tyflos, have solved one of the things that are missing from the usage of canes; the unique feature of this system is that it offers the information about the path in two-dimensional array. This is very useful to overcome the obstacles in the way. This system will inform the user about the obstacles in $\mathrm{x}, \mathrm{y}$ coordinates. Therefore, the height of the object can also be known [13]. They also state that DGPS is another technique, which can be used in their systems to make navigation more accurate for blind users [14]. It offers localization with a precision of around $1 \mathrm{~m} \mathrm{[6].} \mathrm{Another} \mathrm{feature,} \mathrm{which} \mathrm{is} \mathrm{not} \mathrm{present}$ in the smart cane and robotic cane, is to calculate the distance with other people. The researchers who supported the system of CyARM [14] proposed a system that calculates the distance between people to make the blind person's mobility safer.

Robotic cane and many other solutions are often equipped with audio aid of directions and obstacles, which proves futile for deaf users. The researchers who proposed IG [16] gave a very good solution for this. The system provides a quick interpretation of the environment which displayed on the tactile display so that it is quickly explored by the user (Active Touch) [15].

Some existing assistive technologies have been analysed and shown in TABLE 1 , which provides a critical review summary of an extensive evaluation of existing systems with four criteria, which are accuracy, fact, inexpressive and ease of care. A tick $(\sqrt{ })$ indicates strong evidence to suggest the system of such criteria according to specific references; however, a cross $(\mathrm{X})$ means there is no any evidence to suggest this.

Table 1: Evaluation of Solutions

\begin{tabular}{|c|c|c|c|c|}
\hline & Accuracy & $\begin{array}{c}\text { Fast } \\
\text { (based on time) }\end{array}$ & Inexpensive & Easy to carry \\
\hline $\begin{array}{c}\text { Traditional } \\
\text { Low-Tech Aids }\end{array}$ & & & & \\
\hline $\begin{array}{c}\text { Electronic } \\
\text { Travel Aids } \\
\text { Medium Tech } \\
\text { (ETA) }\end{array}$ & & & & \\
\hline $\begin{array}{l}\text { Electronic } \\
\text { Orientation } \\
\text { Aids }\end{array}$ & & & & \\
\hline $\begin{array}{l}\text { Assistance for } \\
\text { Navigation } \\
\text { and Mobility }\end{array}$ & & & & \\
\hline
\end{tabular}

\section{Proposed Solution}

Various studies are underway in the field of web technology with the objective to overcome the difficulties that have been discussed in the preceding section. Some ideas have already been implemented so as to enhance accessibility and usability to support independent mobility of visually impaired and blind people by using the Internet; some of them are internet of things [39], World Wide Web [38], and mobile applications. [38].

These assistive technologies helped for many years; however, now there is the need to create a new assistive technology to help more, especially because the numbers of visually impaired and blind people increase every day [38]. The current times require that solutions be lightweight, easy to use, and fast for increased usage. There is now the need for new assistive technologies to break the relation between high accuracy, less expressive and ease of care; therefore, this study was begun with the concept of assistive technologies that would help the independent mobility of visually impaired and blind people. Similar assistive technologies already exist, but each has its own limitations and disadvantages. Web technologies and mobile applications have been chosen for solving these problems in this study by purposing new assistive technology called supports Independent Mobility of Blind Map 'IMBMap'. 


\subsection{IMBMap}

IMBMap is a web system and mobile application providing interactive map that supports the independent mobility of visually impaired and blind people. It provides users with the facility to search any known or unknown area from a single source without the need to remember. Moreover, IMBMap contains two parts, namely the web system and mobile application; therefore, all of these differing information about visited areas will save on the web system. This means information can be viewed or updated easily using the mobile application IMBMAP as the single source where all visited addresses will be saved automatically. Any updates or deletions can be achieved effectively, and one can effectively keep track of what information is sent out on the web. Moreover, IMBMap provides the service of finding out clear information for all known and unknown areas by giving the information from different secure sources, such as Google Map and user comments, for example.

The scope of this research is based on key principles: (1) concurrent studies in progress; (2) a live project for the development of the solution; and (3) field-testing. This is supported by hard technoeconomic analysis, which ensures that the solution is commercially viable.

IMBMap contains two parts, which are a web system and mobile application, and the connection between both of them in using web services. IMBMap involves the human element from two aspects: the user gets haptic and audio feedback from the mobile application, thereby meaning it is related to the domain of Human Computer Interaction (HCI). Consequently, an original HCI theory has been adapted for the research study whereby there is an amalgamation of scientific research with design research.

\subsection{Applying HCI Theory}

This part of the research focuses on different HCI research approaches and theories regarding the research methods, such as:

5.2.1 User-centered Approach/ Design It are very common for researchers to adopt a user-centered design for their models since it addresses the following aspects:

- Visual design

- Interface design

- Information design

- Interaction design

- Functional specifications

- User needs

- Site objectives [25].
Abras, Krichmar \& Preece state that another important aspect found in user-centered design is the usability testing, which ensures the presence of those aspects that might be expected in a technology by the user [26].

\subsubsection{Different Levels and Planes in the Domain of} Usability Aichholzer \& Strauß categorised the aspects into two main criteria: information-oriented and task-oriented [27]. The divisions of attributes with respect to the five planes proposed by Garrett are stated below [25]:

- Visual design

- Interface design/Navigation design/ Information design

- Interaction design/Information architecture

- Functional specifications/Content requirements

- User needs/ Site objectives.

5.2.3 Frameworks and Models of Human Needs for User Experience Schulze \& Krömker proposed a framework that encompasses a number of important factors concerning human needs with the objective to enhance user experience [28]:

- Relatedness

- Influence and popularity

- Stimulation

- Competencies

- Security

- Autonomy

As shown in Figure 4, Anderson explains the model proposed by Sanders; the prominent demarcations in this model are expert mindset and participating mindset, whereas the other prominent demarcations are design led and research led [29].

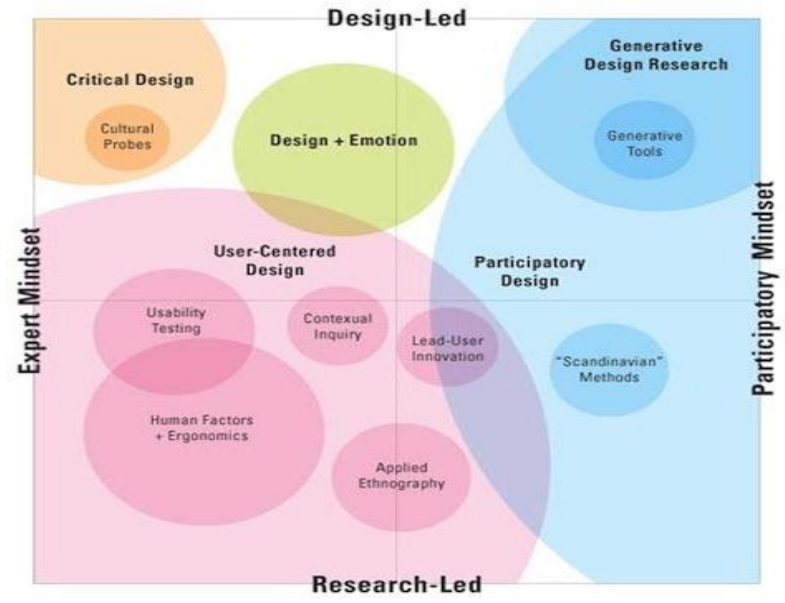

Figure 4: Design research model proposed by Sanders [29] 
The techniques proposed for each demarcation can be seen in Figure 4, with the degree to which overlap may be apparent between the respective demarcations. Besides, Psomas proposes five competencies of user experience design, all of which facilitate the development of an effective design for any technology or system [29]:

1. Information architecture

2. Interaction design

3. Usability engineering

4. Visual design

5. Prototype engineering

It can be seen from these frameworks and models that the focus on the development of a technology is not solely directed on the scientific implementation, but rather on the design features and human requirements to improve the user's entire experience. Mackay \& Fayard considered HCI as a perfect amalgamation of both scientific implementation and design features of any technology or system [30]; therefore, HCI has been chosen as the most appropriate for this research study. In addition, they also stated that HCI cannot be termed as a pure science owing to the fact that it also caters to the human aspects related to technology, as opposed to only naturally occurring events (which are usually witnessed in scientific practices).

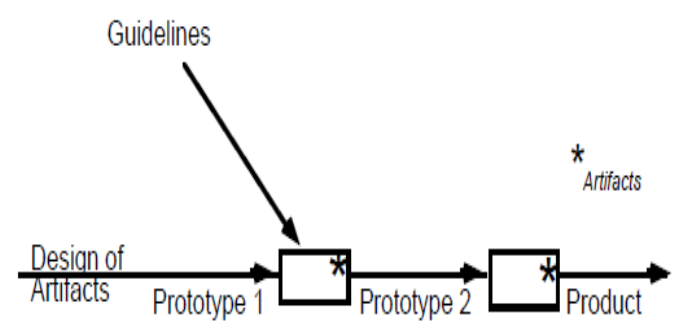

Figure 5: Inclusion of guidelines in the design process of any system or technology [30]

It can be seen from Figure 5 that the design research for any system involves the inclusion of guidelines that guide the researcher to improve the design in the light of users' requirements. This approach is commonly adopted by researchers in present times. The following applications are amongst a few of the examples:

- Hoven et al. discussed an example of a technology that improved the product for users due to the inclusion of scientific and design research [31]. The technology was aimed towards delivering service to youngsters diagnosed with degenerative muscle disease. As a result of this disease, the patients were required to exercise the same workouts, which became boring and tedious after a certain time period. In an endeavour to make the technology more interesting, design research was conducted to facilitate changes in the technology with the objective of making it more appealing for young patients. As a result of the design research, video game activities were included in the workouts and presented to the patients whilst they continued their exercises.

Figure 6 includes the amalgamation of design and scientific research models, which is known to produce effective results relating to $\mathrm{HCI}$ :

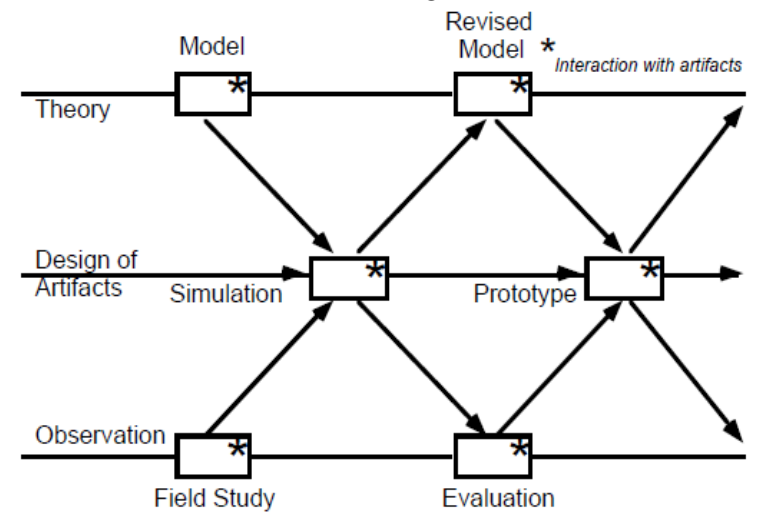

Figure 6: Amalgamation of design and scientific research models [30]

The boxes in Figure 6 represent figures that are commonly found in the real world:

Model: A research may devise a phenomenon from the realities of the world, and accordingly aim to develop a framework or model to explain such. Mackay \& Fayard explained two models - the deductive model and inductive model - with respect to HCI practices [30]. The deductive model is defined as the more general model, tending to explain the general theories and real world phenomenon; the inductive model observes the prevailing concept in the real world without being affected by pre-defined theories and notions. Following the materialisation of the observations, a model is proposed to describe the phenomenon under discussion.

Observations/ Field Study: Observations can be defined as those notions established as a result of examination and analysis. Mackay \& Fayard state that scientists and researchers make use of observations and past theories in order to explain and present their newly developed theories to the world [30]. Moreover, Villiers provides some information regarding the techniques used to evaluate online platforms; users thinking aloud, protocol analysis (verbal reports considered as important data), and walkthroughs, to name a few [32].

Simulations: Yusoff defines simulations as the form of testing that enables users to provide feedback on the basis of which changes can be incorporated into the system [33]. It is due to simulations that the mode of operations can be 
tailored to user requirements in an effective manner. Simulations may range from simple computer-based experiments (for testing basic academic concepts) to technically advanced virtual realities, as shown in Table 2.

Table 2: Types of Simulations

\begin{tabular}{|c|c|c|}
\hline $\begin{array}{l}\text { Simulation } \\
\text { Technique }\end{array}$ & Advantages & Disadvantages \\
\hline 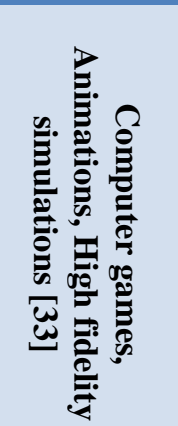 & $\begin{array}{l}\text { These } \\
\text { environments } \\
\text { offer engaging } \\
\text { scenarios and } \\
\text { platforms [33]. } \\
\text { Such } \\
\text { technologies } \\
\text { allow the user to } \\
\text { be more } \\
\text { productive [33]. }\end{array}$ & $\begin{array}{l}\text { Sometimes, this } \\
\text { mode does not } \\
\text { produce } \\
\text { successful results } \\
\text { [33]. }\end{array}$ \\
\hline 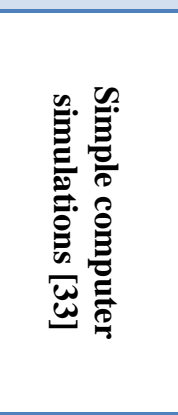 & $\begin{array}{l}\text { Learners get a } \\
\text { free trial version } \\
\text { to comment upon } \\
\text { and use [33]. }\end{array}$ & $\begin{array}{l}\text { Simulation can be } \\
\text { made to adopt } \\
\text { different } \\
\text { scenarios; } \\
\text { however, } \\
\text { developers } \\
\text { usually do not opt } \\
\text { for such flexible } \\
\text { modes of } \\
\text { operability [33]. }\end{array}$ \\
\hline 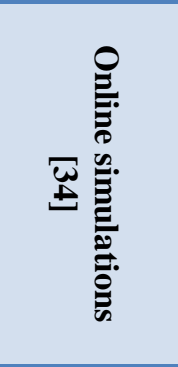 & $\begin{array}{l}\text { Students and } \\
\text { professionals can } \\
\text { understand } \\
\text { concepts that } \\
\text { might be difficult } \\
\text { to grasp with the } \\
\text { help of } \\
\text { conventional } \\
\text { modes [34]. }\end{array}$ & $\begin{array}{l}\text { Online } \\
\text { simulations may } \\
\text { inhibit the natural } \\
\text { process of } \\
\text { learning that is } \\
\text { achieved in a } \\
\text { classroom setting } \\
\text { [34]. }\end{array}$ \\
\hline
\end{tabular}

Prototypes: Prototypes are defined as the means of expressing the design artefacts of any system or technology prior to the whole product being released; this facilitates different design options in which the product can be developed [35]. There are different categories of prototype. A few of the most common ones include role, integration, implementation, and look and feel prototypes [35]:

- Role refers to the relevance of the technology or service in the lives of users or the part that is played by the technology to facilitate any task in their lives.

- 'Look and feel' refers to the investigation concerning the design, and the experience attained after using the system or the technology.
- Implementation brings out the questions concerned with the techniques and modes adopted by the technology or system to perform its task; it mainly involves the strategies adopted by the technology to provide service to its users.

Evaluation: Evaluation refers to the concept of analyzing the overall perceived credibility and relevance of a system or technology in consideration of its users [35]. Evaluation assesses the benefits, limitations, and constraints of the technology [35]. Good theoretical evaluations offer practicality in a wide range of situations [36], and thus their importance in the evaluation of a framework, model or system cannot be overemphasized.

Users are the individuals who utilize the technology and subsequently face the possible limitations that might become apparent in due course of usage; the constraints might also be faced as a result of the uniqueness of their own traits and physical attributes. User evaluation methods tend to judge the overall relevance and suitability of the technology with regard to such personal aspects; however, there exist experts in every domain who have gained commendable knowledge in a certain field via means of multiple years' experience or research activities. In this way, experts tend to evaluate technologies on the basis of their knowledge and their perceptions of a good quality framework, model or system. The expert might evaluate a certain technology in his own domain: for example, a researcher who possesses extensive knowledge in the field of usability will be able to conclude relevant findings regarding the level of usability of a certain technology as opposed to its security. There are various types of evaluation method such as:

- Realistic evaluation focuses on the preference and usability context with regard to the manner of use of the system under evaluation. Realistic method of evaluation not only considers what works, but for whom and in what way and in which context [36]. Through realistic evaluation, it is possible to establish to whom the responsibility of implementing a new framework falls and consider these factors in the analysis by selecting a focused group of experts. This method is a low cost, fast application.

- Deliberative democratic evaluation seeks to arrive at unbiased evaluative conclusions through engagement of the main stakeholders, and sometimes employs the use of other evaluation methodologies [36]. Deliberative democratic evaluation relies on evaluation methods, such as a wide range of expert judgment that seeks to maximize the 
social implications of the suggested framework's components [37].

- An empowerment evaluation method would focus on helping a particular group of stakeholders, either clients seeking service through the system or providers of the system's services. In addition, empowerment method takes into consideration feedback from different stakeholders and selected participants [36].

- Utilization-focused evaluation perpetuates the belief that evaluations are because of usefulness of the system to the end-user [36]. If a wide range of user opinions, rather than expert opinions, on a model or system is an influencing factor to the change, this method would be supremely important.

\section{Conclusion and Further Work}

Displacement from one place to the other can often be considered a challenge by some blind people. In order to make this task easier for the blind people many technological solutions have been proposed over the years that are called Assistive Technologies. These tools and devices assist the blind users to make displacements from one place to place while overcoming obstacles safely.

Many solutions languish in the dark tunnels of academic history and gather dust for not being commercially viable; therefore, the present study encompasses the entire gamut of the subject surrounding the problem. These constitute a critical review of the literature, development of a solution as a live project, inclusion of the requirements of visually impaired and blind people, field-testing the models, and techno-economic feasibility analyses. This paper focuses on background information and the methodology; future papers will provide more detail about design, implementation and testing the web system and mobile application for the IMBMap.

\section{References}

[1] W. A. Rogers, M. A. O'Brien, A. C. McLaughlin, "Selection and Design of Input Devices for Assistive Technologies", IEEE, 2006.

[2] R.Nagarajan, S. Yaacob and G.Sainarayanan, "Role of Object Identification in Sonification System for Visually Impaired," IEEE, 2003

[3] E. Pissaloux, "A Characterization of Vision Systems for Blind People Mobility", IEEE, 2002

[4] M. R. Lightner, D. Erdogmus, "Signal Processing Challenges in Cognitive Assistive Technology", IEEE Signal Processing Magazine September 2008, 2008
[5] D. J. Calder, "Assistive Technology Interfaces For The Blind", 3rd IEEE International Conference on Digital Ecosystems and Technologies, 2009

[6] E. Pissaloux, "Assistive technologies to support independent mobility of visually impaired”, IEEE, 2002.

[7] A. Y. J. Szeto, "A Navigational Aid for Persons with Severe Visual Impairments: A Project in Progress", Proceedings of the 25* Annual International Conference of the IEEE EMBS, Caneun, Mexico. 2003

[8] P. E. Lanigan, A. M. Paulos, A. W. Williams, D. Rossi, P. Narasimhan, "Trinetra: Assistive Technologies for Grocery Shopping for the Blind”, IEEE, 2006.

[9] A. Honda, T. Shiose, Y. Kagiyama, H. Kawakami, O. Katai, "Design of Human-Machine System for estimating pattern of white cane walking", ICROS-SICE International Joint Conference, 2009.

[10] L. K. Au, W. H. Wu, M. A. Batalin, W. J. Kaiser, "Active Guidance Towards Proper Cane Usage", Proceedings of the 5th International Workshop on Wearable and Implantable Body Sensor Networks, 2008

[11] K. Ito, M. Okamoto, J. Akita, T. Ono, I. Gyobu, T. Tagaki, T. Hoshi, Y. Mishima, "CyARM: An alternative aid device for blind persons," Proc. CHIO5, Portland, OR, pp. 1483-1488, 2005

[12] W. C. Mann, S. Goodall, M. D. Justiss, M. Tomita, "Dissatisfaction and nonuse of assistive devices among frail elders", Assistive Technology, 14:130 - 139, 2002

[13] D. Dakopoulos, N. Bourbakis, "Towards a 2D Tactile Vocabulary for Navigation of Blind and Visually Impaired", Proceedings of the 2009 IEEE International Conference on Systems, Man, and Cybernetics San Antonio, TX, USA, 2009

[14] D. Dakopoulos, N. G. Bourbakis, 'Wearable Obstacle Avoidance Electronic Travel Aids for Blind: A Survey", IEEE Transactions on systems, Man, and CYBERNETICS, VOL. 40, NO. 1, 2009.

[15] E. Pissaloux, A vision system design for blind mobility assistance, Proc. of IEEE-EMBC, Houston, TX, USA, pp 2349-2350, 2002.

[16] R.Velazquez, E. Fontaine, Coding the Environment in Tactile Maps for real-time guidance of the visually impaired., IEEE, 2005

[17] K. Iwatsuka, "Development of a Guide Dog System for the Blind", IEEE, 2004, http://doi.ieeecomputersociety.org/10.1109/CCCRV.200 4.1301475

[18] G. E. Hendershot, J. E. Crews, "Toward International Comparability of Survey Statistics on Visual Impairment: The DISTAB Project", Journal of Visual Impairment and Blindness, 2006

[19] W. Wu, L. Au, B. Jordan, T. Stathopoulos, M. Batalin, W. Kaiser, A. Vahdatpour, M. Sarrafzadeh, M. 
Fang, J. Chodosh. "The smartcane system: An assistive device for geriatrics. Third International Conference on Body Area Networks", March 13-17, 2008.

[20] O. Lahav, D. W. Schloerb, S. Kumar, M. A. Srinivasan, "BlindAid: a Learning Environment for Enabling People who are Blind to Explore and Navigate through Unknown Real Spaces", IEEE, 2008

[21] R.D. Easton, B.L. Bentzen, "The effect of extended acoustic training on spatial updating in adults who are congenitally blind", Journal of Visual Impairment and Blindness, 93(7), pp. 405-415, 1999

[22] S. Landau, W. Wiener, K. Naghshineh and E. Giusti, "Creating Accessible Science Museums With User Activated Environmental Audio Beacons (Ping!)," Assistive Technology, 17, pp. 133-143, 2005.

[23] I. Shim, J. Yoon, "A Robotic Cane based on Interactive Technology”, IEEE, 2002

[24] F. Wong, J. S. Zelek, "Tactile \& Inertial Patterns from a Long White Cane", IEEE, 2006

[25] Garrett, J. J. (2011). The Elements of User Experience: User-Centered Design for the Web and Beyond (Second Edi.). Berkeley: Peachpit Press.

[26] Abras, C., Maloney-krichmar, D., \& Preece, J. (2004). User-Centered Design. Bainbridge, W. Encyclopedia of Human-Computer Interaction, Thousand Oaks: Sage Publications, pp. 1-14.

[27] Aichholzer, G., \& Strauß, S. (2009). Understanding a Complex Innovation Process: Identity Management in Austrian E-Government. Proceedings of the 10th International Digital Government Research Conference (pp. 230-239).

[28] Schulze, K., \& Krömker, H. (2010). A Framework to Measure User Experience of Interactive Online Products. Proceedings of Measuring Behavior.

[29] Anderson, R., (2011). User Experience Research, Design Research, Usability Research, Market Research: A Changing, Interconnected World. UX Magazine. Retrieved from http://uxmag.com/articles/user-experience-researchdesign-research-usability-research-market-research

[30] Mackay, W., \& Fayard, A. (1997). HCI , Natural Science and Design: A Framework for Triangulation Across Disciplines. Designing Interactive Systems, , 223-234.

[31] Van den Hoven, E., Frens, J., Aliakseyeu, D., Martens, J.-B., Overbeeke, K., \& Peters, P. (2007). Design research \& tangible interaction. Proceedings of the 1st international conference on Tangible and embedded interaction - TEI '07, pp.109. New York, USA: ACM Press. doi:10.1145/1226969.1226993

[32] Villiers, P. C. D. (2000). Using HCI techniques to evaluate Electronic Commerce sites. University of Pretoria.

[33] Yusoff, A., Crowder, R., Gilbert, L., \& Wills, G. (2009). A Conceptual Framework for Serious Games. 2009 Ninth IEEE International Conference on Advanced Learning Technologies (pp. 21-23). IEEE. doi:10.1109/ICALT.2009.19

[34] Bell, R. L., \& Smetana, L. K. (2008). Using Computer Simulations to Enhance Science Teaching and Learning. Technology in the Secondary Science Classroom, National Science Teachers Association, pp.23-32.

[35] Houde, S., \& Hill, C. (1997). What do Prototypes Prototype?. Handbook of Human-Computer Interaction, 2nd Ed.

[36] Contandriopoulos, D., \& Brousselle, A. (2012). Evaluation models and evaluation use. Evaluation, 18(1), pp. 61-77.

[37] Ruegg, R., \& Jordan, G. (2007). Overview of evaluation methods for $\mathrm{R}$ and $\mathrm{D}$ programs. U.S. Department of Energy, (March), pp.18.

[38] Assistive Technologies to Support Independent Mobility of Visually Impaired and Blind People. The World Congress on Special Needs Education (WCSNE2015). Philadelphia, USA.

[39] Evaluation of the UTAUT model for acceptable user experiences in e-Government physical and virtual identity access management systems. In, 8th IEEE International Conference for Internet Technology and Secured Transactions (ICITST-2013), London, GB. 